\title{
Rangeland Inventory as a Tool for Science Education
}

\section{Program pairs range professionals, teachers and students together to conduct vegetation measurements and teach inquiry-based science.}

\author{
By Juley Hankins, Karen Launchbaugh, and Gretchen Hyde
}

$\mathrm{M}$ any people perceive rangeland management as a profession solely focused on livestock production (1). If this narrow view continues, society may deem rangeland specialists unable to effectively manage rangelands in the face of the evolving public values and uses. As our population becomes more urbanized, familiarity with natural resources and their management is often lost. This new audience of urban and suburban rangeland dwellers needs knowledge to understand the natural processes and management of rangelands that surround them (2).

Rangeland managers have gained a wealth of knowledge about how plants, fire, grazing, water, and climate interact in natural systems. However, to gain public support for management decisions, rangeland professionals need to help others understand how rangelands work; how they are maintained, and how they respond to change. Studying rangeland vegetation in school classes is one way to showcase the diversity of rangeland resources and the work that rangeland specialists perform. Agricultural technology, biology, and general science classes are good avenues for studying rangeland management and ecology.

In Idaho, we recently created and distributed a rangeland education program for use in middle school and high school science classes. We started by examining the most widely used natural resource and environmental education programs for curricula related to rangelands. We quickly learned that very little information about rangelands exists in current science education programs. There are several rangeland projects and activities created by educators and range professionals but, we could not find any comprehensive range education programs that met our needs. Therefore, we started drafting an education program focusing on rangeland vegetation inventory and monitoring.

Once the topics were selected, the general structure of the program and its components were developed. Drafts of the program components were field-tested by students and rangeland specialists and modified. After appropriate revisions, the program was presented to teachers at training workshops.

The first goal of this rangeland education program was to spark an interest in rangeland science and management among middle school and high school students. Another goal for this program was to increase a "sense of place" and give students a heightened understanding and awareness of their local environments. "Sense of place" is defined by Sanger (3) as "an experientially based intimacy with the natural processes, community, and history of one's place." It is disconcerting that students often learn more about South American rainforests than the rangelands in their own back yards. We believe a rangeland education program based on vegetation 
inventory could give teachers tools to explore local rangeland environments with their students.

\section{Elements of an Effective Environmental Education Program}

To create a viable rangeland education program, we first studied several environmental and natural resources education programs. The major environmental/natural resources education programs in use

\section{Rangeland Vegetation Inventory as Scientific Inquiry}

The basic tenet of inquiry-based (also known as problem- or project-based) science teaching is that students learn science processes by actively performing them. Students collect data, develop questions, and present their results. Teachers become "coaches" that guide students as they discover what they need to know and do to answer their own questions. A classic inquiry-based science experiment involves measuring and monitoring heart rates of class members. The first set of pulse measurements demonstrate to the class that each student's resting pulse is unique to that student. Several variables affecting heart rate include the individual's metabolism, body size, age, physical fitness, recent intake of caffeine or other chemicals, recent physical activity, etc. The first resting pulse is only a starting point; a baseline measurement. When all students' resting heart rates are compared, students begin to make connections between their heart rates and the variables at work on each of them. Students can begin developing ideas for experimenting with the different heart rate variables. One group might measure the heart rate of the same person over time while changing their activity level. Another group may compare several students of varying body sizes after controlling as many other variables as possible. The pulse rate experiment is a good analogy for designing an inquiry-based study of rangeland vegetation. The differences in individual heart rates are similar to the natural variations in vegetation and ecological inventory measurements taken on different range sites. Each range site has characteristics that make it unique, like each student's pulse. These characteristics include location, climate, soil type, topography, present vegetation, and current or past land uses. The "pulse," or responding variable, of rangeland vegetation includes basic vegetation attributes, such as cover, biomass, density, frequency, and species composition. Once students compile and study their inventory data, they can look for connections or correlations between physical characteristics or land uses and differences in the vegetation attributes they measured. They can also form range research questions that require further data collection and analysis. today can be separated into two categories: activityor inquiry-based. Most programs are activity-based, for example, Projects WET (4), WILD (5), and Learning Tree (6). These programs are compilations of relatively short activities organized into themes.

The GLOBE (7) and SITE (8) programs are examples of inquiry-based protocols that involve students conducting experiments and collecting and analyzing data. Students also report their findings to scientists, government officials, land managers, or other students.

All of the programs discussed above are effective, engaging and nationally recognized environmental education efforts. While their approaches to natural resources education may differ, their basic elements are quite similar. Based on reviews of existing programs and environmental education literature, the following are key elements needed for an effective rangeland education program.

- Interested, knowledgeable, and skilled teachers. Teachers should have adequate training about rangeland ecology and issues, support personnel, background materials, and should be interested and excited about rangelands in some way. Teachers tend not to teach topics they do not understand or in which they are not interested (9).

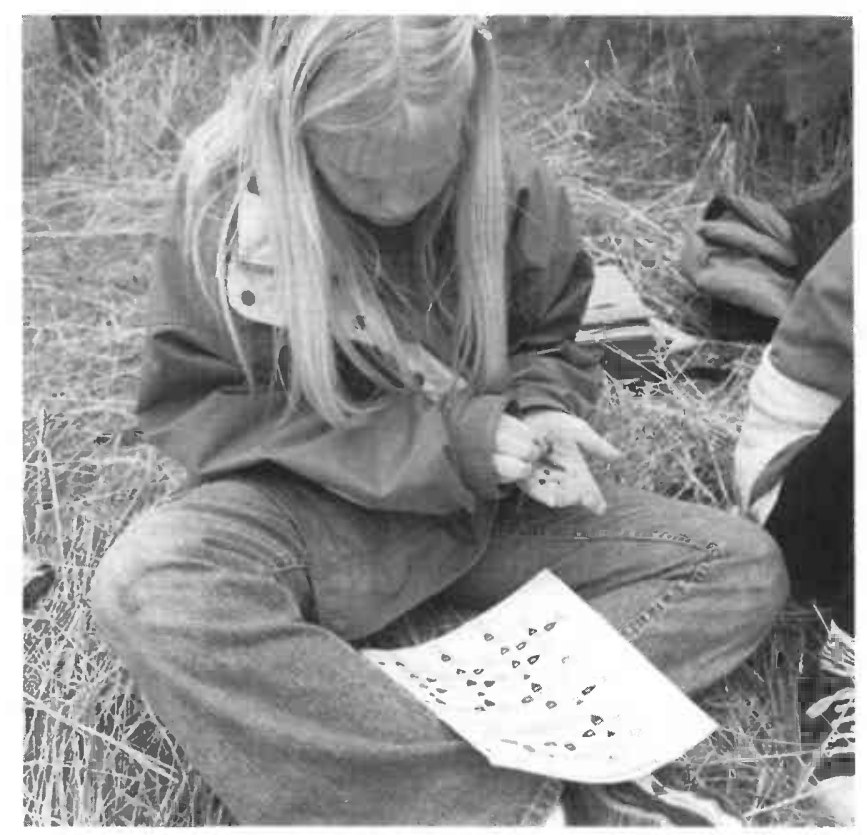

Figure 1. A $6^{\text {th }}$ grade student determines soil texture as part of the site inventory. 
- Student-centered, inquiry-based learning. Student-centered or constructivist learning changes the role of the teacher from lecturer to facilitator. Facilitators do not give students answers; they provide resources for students to find the answers. Students conduct their own experiments and collect real data that they analyze or use to complete the project. Inquiry-based, student-centered learning can lead to deeper understanding of information (10). Student understand the information because they "own" it (Fig 1).

- Integration and transfer of skills. Well designed projects require students to use knowledge and skills learned in classes including science, math, social studies, and geography, to gather and analyze information needed to complete the project or solve a problem (11).

- A sense of place, or connections to the local environment. Students who understand the ecology and issues of their area are more likely to become active, responsible citizens of their community (3).

In brief, the success of an education program begins with an enthusiastic teaching professional who has support from resource specialists to implement the program. Students learn new skills through hands-on participation in field activities that complement skills learned in the classroom, adding to their understanding of the environment. Teachers' logistical limitations and curriculum constraints also need to be considered. An effective program needs to be easy for teachers to use and understand, and meet curriculum content requirements.

\section{A Rangeland Education Program Emerged}

We developed a complete rangeland vegetation inventory program including a field lab manual, a supplemental plant identification guide, equipment kits, and a training workshop with follow-up assistance (Fig. 2). The field labs engage students in the measurement of basic vegetation and site attributes, including ground cover, biomass, plant species inventory, and ecological site inventory. The field labs are essentially self-contained, including the equipment needed to complete the field labs and a lab manual with data sheets and background information.

The field lab manual presents introductory information about rangeland inventory and monitoring,

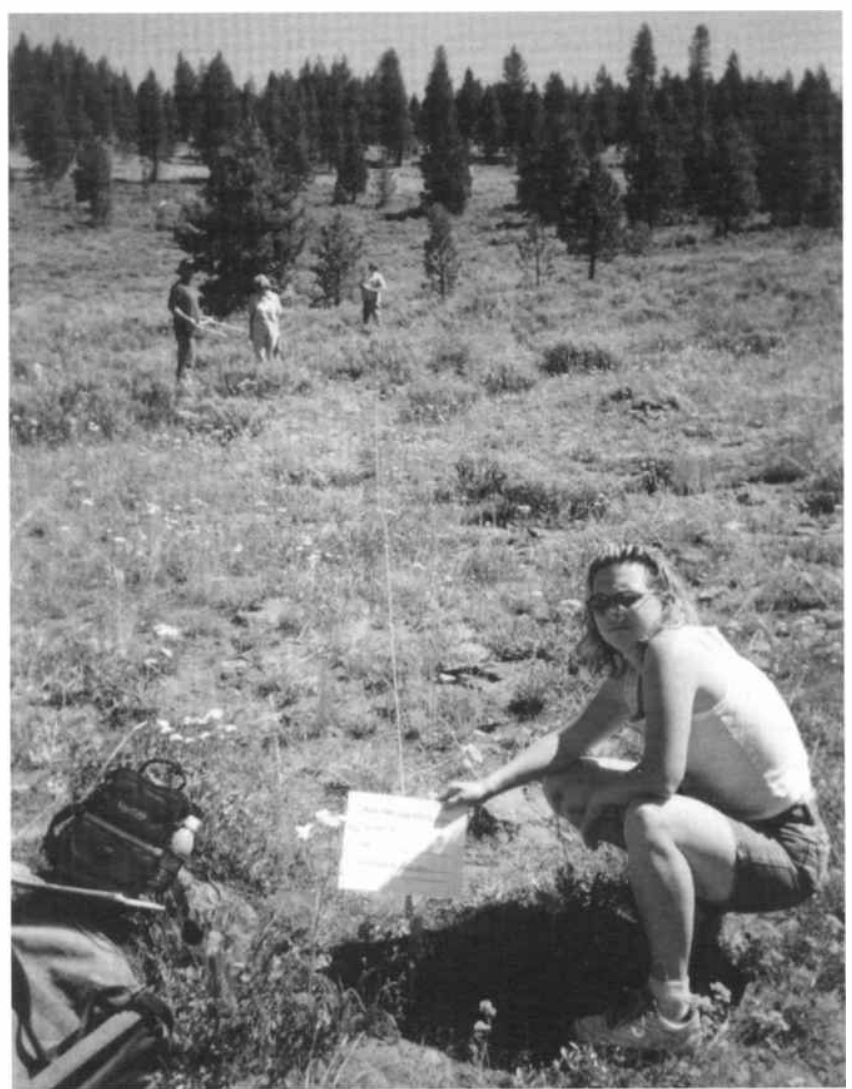

Figure 2. Teachers performing vegetation inventory protocols in central Idaho.

instructions on selecting study sites, and detailed descriptions of field methods. Four protocols were designed including a site inventory, biomass estimation, ground cover estimation, and plant species inventory. The protocols were designed to enable people without range expertise to perform scientific investigations on rangelands. After collecting "baseline" rangeland vegetation data, students can pose range research questions and analyze data to answer questions. Data collected using these protocols can be analyzed in several ways, including comparisons of different study sites, estimating carrying capacity and forage suitability for various herbivores, or tracking noxious weeds.

When developing the field labs, a balance was struck between scientific accuracy and ease of use for inexperienced practitioners. The inventory of rangeland vegetation attributes had to be pared down to a model that provided simple, objective, and reasonably accurate data for analysis. The protocols were designed with the limitations of a junior or senior-high school class in mind. The techniques 
and equipment were designed to be scientifically valid for most of Idaho's rangeland types. These include basic vegetation assessments that could be applied on rangelands across western North America with little or no adaptation.

\section{Rangeland Assessment Protocol Details}

The site inventory protocol provides both ecological and management information about the selected study site. Information collected in the site inventory includes physical location and topographic and abiotic features of the site. Photographs of the study area and survey transects are also included. Site inventory data describes the location and basic physical characteristics of the study sites and allows for comparison with other study sites.

Ground cover is estimated using a line-point method (12) where "hits" are recorded every 3 feet along a 100 -foot transect line (or every meter on a 30 -meter transect). Each point is counted in one of several cover classes including: grasses, grass-likes, forbs, woody plants (shrubs and trees), rock, bare ground, and litter.

The biomass protocol involves clipping four, 2.7 $\mathrm{ft}^{2}\left(0.25 \mathrm{~m}^{2}\right)$ square plots along each transect line on the study site and separating the clipped vegetation into grasses, grass-like plants, forbs, and shrubs (13). The samples are weighed and biomass is estimated for the site. A conversion chart is used to estimate dry weight based on field weight of specific vegetation types and growth stages (14).

A plant species inventory is the only attribute of the inventory protocol that requires plant identification. When a plant cannot be identified in the field, it can be collected and pressed for later study and identification. The plant species inventory requires ranking the 5 to 7 most abundant species on the site. Any noxious weeds present on the site are also recorded.

A basic plant guide by Hankins titled, "Backpack Guide to Idaho Range Plants" was developed to supplement the rangeland vegetation inventory protocol. The guide includes 75 of the most common and abundant rangeland plants of Idaho. Each plant has a clear, easy to understand description, and a detailed drawing to aid in identification. The guide also includes plant identification diagrams, instructions, and activities.

Equipment kits were developed to accompany the field labs. The kits include materials that are sim-

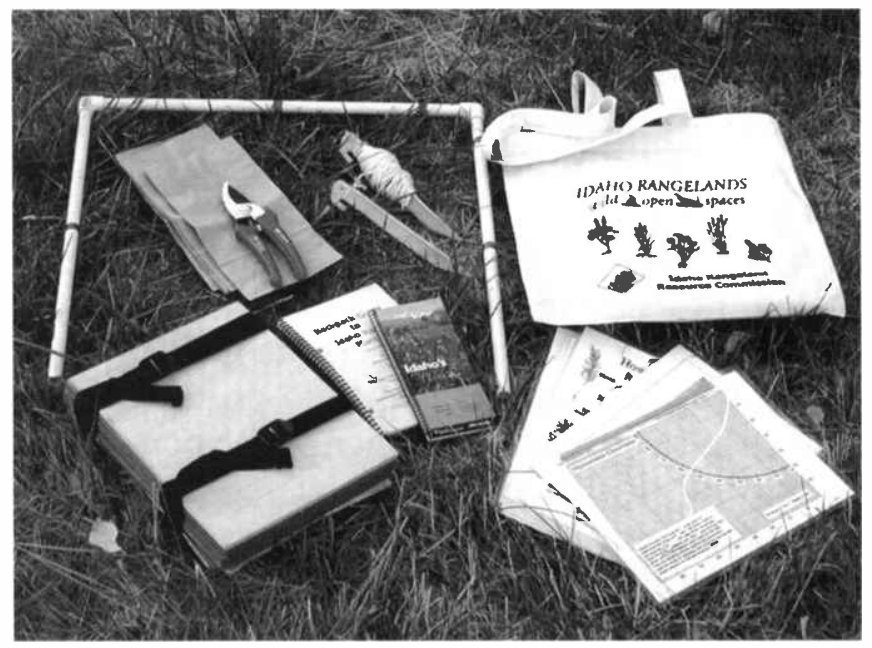

Figure 3. Contents of the range assessment equipment kit.

ple, inexpensive, widely available, durable, and reasonably safe for student use. The kits include: a 100-foot (or 30-meter) transect line, a $20 \times 20$ inch (or $50 \times 50 \mathrm{~cm}$ ) square collapsible three-sided plot frame made from PVC pipe, bypass pruning shears, paper bags for biomass samples, Prather's Idaho Noxious Weeds book, Hankins' Backpack Guide to Idaho Range Plants, a 9 by 12 inch plant press, Soil Texture by Feel Analysis worksheet, clinometer (adapted from the GLOBE program), photo label sheet, map of Kuchler Potential Natural Vegetation for Idaho, map of average annual precipitation for Idaho, and a tote bag to carry everything (Fig. 3). For details on how to make a Rangeland Inventory Kit visit www.idrange.org and click on "Teacher Resources."

\section{Uses, Goals, and Challenges of this Program}

Teachers are using the rangeland vegetation inventory program in several ways. A few teachers have adapted the protocols for mapping infestations of noxious weeds around their schools. Some are working with county weed supervisors to study the effects of various treatments on target weeds and associated vegetation. Others are estimating stocking rates of grazing lands for livestock and wildlife. One teacher adapted the biomass and cover protocols for her students to conduct an economic analysis of producing hay on her own land.

Since we started training Idaho teachers in rangeland inventory in 2000 , we have distributed over 250 vegetation inventory kits. Our best response has been from teachers of vocational agriculture, 
advanced science, and elective sciences such as botany, environmental science, and watershed analysis. We believe this is because teachers of these classes have more flexibility when designing their curriculum.

The rangeland inventory protocol has been implemented, in its entirety, in less than a dozen high schools. However, many teachers are taking advantage of the flexibility of the field protocols, and using them as templates to design vegetation studies specific to their area, needs, and interests.

The primary challenge in developing a rangeland science education program is presenting a complex body of knowledge about rangeland vegetation ecology to teachers and students in a simple, meaningful way. The solution in this project was to develop a basic rangeland vegetation inventory model that fits the needs of educators. This includes simple, consistent, and scientifically valid data collection equipment and techniques. A true understanding of rangeland vegetation ecology often takes years of experience and/or college degrees to acquire. Instead of trying to teach a lifetime of range vegetation knowledge in a two-week science unit, the emphasis of this program is on the scientific inquiry process.

The next challenge is to motivate rangeland professionals and teachers to work together. Teachers cannot become experts in rangeland science overnight. Rangeland professionals need to make their expertise available to students and teachers. Working with schools and sharing knowledge of rangeland science and management may be a step toward improved public relations and understanding of "wild open spaces."

\footnotetext{
About the Authors: Juley Hankins created this inventory project as part of her MS degree in Rangeland Ecology and Management at the University of Idaho under the supervision of Dr. Karen Launchbaugh. Hankins in now an employee of the Bureau of Land Management. Gretchen Hyde is the Executive Director of the Idaho Rangeland Resource Commission which suggested and supported this project. The authors would like to thank Angie Freeman, Lovina New, and Rachel Frost for editorial suggestions and technical assistance in preparing this paper.
}

\section{References}

1. Kreuter, U.P. and M.P. Schellenberg. 2001. Charting our changing course. Rangelands. 23:22-29.

2. Hart, R.H. 1996. Can we broaden the rangeland audience without denying our grazing heritage? Rangelands. 18:173-176.

3. Sanger, M. 1997. Viewpoint: Sense of place and education. J. Environ. Educ. 29:4-8.

4. The Watercourse and the Council for Environmental Education. 1995. Project WET: K-12 Curriculum and Activity Guide. Bozeman, MT, and Houston, Texas. Available online at:< http://www.projectwet.org/> Accessed 20 October, 2003.

5. Western Association of Fish and Wildlife Agencies and the Council for Environmental Education. 1992. Project WILD: K-12 Activity Guide. Bethesda, MD: Council for Environmental Education. Available online at: $<$ http://www.projectwild.org/> Accessed 20 October, 2003.

6. American Forest Foundation. 1992. Project Learning Tree. Washington D.C.: American Forest Foundation and the Council for Environmental Education. <http://www.affoundation.org/> Accessed 20 October, 2003.

7. GLOBE Leadership Council. 1997. Global Learning and Observations to Benefit the Environment. Washington D.C. <http://www.globe.org.uk/> Accessed 20 October, 2003.

8. Beckwith, R. E. 1997. Project SITE (Students Investigating Today's Environment) Student Manual (2nd Ed.). Boise, Idaho: Southwest Idaho School to Work Partnerships.

9. Knapp, D. 2000. The Thessaloniki Declaration: A wakeup call for environmental education? J. Environ. Educ. 31:32-39.

10. Lord, T. R. 1999. A comparison between traditional and constructivist teaching in environmental science. J. Environ. Educ. 30:22-28.

11. North American Association for Environmental Education. 1998. Environmental Education Materials: Guidelines for Excellence. Troy, OH.

12. Heady, H.F., R.P. Gibbens, and R.W. Powell. 1959. A comparison of the charting, line intercept, and line-point methods of sampling shrub types of vegetation. J. Range. Manage. 12:180-188.

13. Bureau of Land Management. 1996. Sampling Vegetation Attributes: Interagency Technical Reference. Cooperative Extension Service, USDA Forest Service, USDA Natural Resources Conservation Service Grazing Land Technology Institute, USDI Bureau of Land Management. Publication No. BLM/RS/ST-96/002+1730.

14. Natural Resources Conservation Service, Grazing Lands Technology Institute. 1997. National Range and Pasture Handbook. Washington DC: United States Department of Agriculture. Publication No. 190-vi-NRPH. 